\title{
Eyelid Melanoma
}

National Cancer Institute

\section{Source}

National Cancer Institute. Eyelid Melanoma. NCI Thesaurus. Code C4358.

A melanoma that arises from the upper or lower eyelid. 